\title{
Определение оптимальной структуры капитала на примере финской компании Alma Media Corp. и российской компании «РБК Информационные системы»
}

\author{
Животова Е.Л. ${ }^{56}$, Алексеев А.А. ${ }^{57}$, Протасов В.С. ${ }^{58}$, Ламминен Е. ${ }^{59}$
}

В статье представлено исследование по определению оптимальной структурь капитала для компаний Alma Media и РБК и ее сравнению с фактической структурой капитала. При анализе использовань методы EBIT-EPS, операчионного дохода и скорректированной приведенной стоимости (APV). В ходе работы было выявлено, что в обоих случаях менеджментом компаний принимались решения, противоположные теоретически обоснованным. Неэффективные решения, которые привели к уменьшению стоимости компаний, были обусловлены интересами контролирующих акционеров Alта Media и РБK.

\section{$J E L: G 32$}

Ключевые слова: оптимальная структура капитала, фактическая структура капитала, медиа-отрасль, стоимость долга, метод анализа затрат на капитал

\section{Введение}

В настоящей статье будет рассмотрено два кейса по выбору оптимальной структуры капитала финской компании Alma Media и российской «РБК Информационные системы». Целью нашей работы было определить соотношение между решениями о структуре капитала, принимаемыми менеджментом компании, и оптимальной структурой капитала, определяемой исходя из существующих теоретических моделей.

Для достижения этой цели решались следующие задачи:

- выявить точки, в которых рассматриваемые компании стояли перед выбором между использованием собственного или заемного капитала;

- определить оптимальную структуру капитала Alma Media и РБК;

- проанализировать решения, принятые менеджментом компаний;

- определить степень соответствия оптимальной и фактической структур капитала и объяснить причины их расхождения;

- сравнить результаты, полученные для Alma Media и РБК.

Выбор для анализа компаний Alma Media и РБК обусловлен несколькими причинами. С одной стороны, особый интерес представляет сравнение компаний из России и Финляндии, которые, несмотря на определенную географическую и историческую общность, существенно отличаются по степени развитости экономики и культуре ведения бизнеса. Для того чтобы провести корректное сравнение, необходимо было найти аналогичные, работающие в одной и той же отрасли компании в России и Финляндии. Одна из немногих отраслей, которые хорошо развиты в обеих странах, - телекоммуникационная и

\footnotetext{
${ }^{56}$ Стажер-исследователь Лаборатории корпоративных финансов кафедры экономики и финансов фирмы, ГУВШЭ.

${ }^{57}$ Стажер-исследователь Лаборатории корпоративных финансов кафедры экономики и финансов фирмы, ГУВШЭ.

${ }_{58}$ Стажер-исследователь Лаборатории корпоративных финансов кафедры экономики и финансов фирмы, ГУВШЭ.

${ }^{59}$ Стажер-исследователь Лаборатории корпоративных финансов кафедры экономики и финансов фирмы, ГУ ВШЭ.
}

Выпуск \#4(8), 2008

() Электронный журнал Корпоративные Финансы, 2008 
медиаотрасль. Рассмотрев пул существующих участников рынков двух стран, которые котируются на бирже (следовательно, предоставляют необходимую нам отчетность), мы пришли к выводу, что наиболее близкими по структуре бизнеса, размеру и времени принятия решения являются Alma Media и «РБК Информационные системы».

В первой части статьи будет определена оптимальная структура капитала для компании Alma Media, проведено сравнение с фактической структурой капитала и выявлены причины их расхождения. Во второй части работы аналогичный анализ будет сделан для «РБК Информационные системы». В третьей части будет проведена сравнительная характеристика оптимальной и фактической структур капитала, а также их соотношения для двух компаний. И в последней части мы сделаем выводы о причинах расхождений оптимальной и фактической структур капитала и выскажем гипотезу об особенностях принятия управленческих решений в России и Финляндии.

\section{Определение оптимальной структуры капитала для компании Alma Media}

В 1998 году произошло слияние компаний Aamulehti и MTV3, в результате чего образовалась компания Alma Media. Акции новой компании котировались на фондовой бирже Хельсинки. Слияние компаний не оказало влияния на стоимость компании. На 2004 год крупнейшими акционерами компании являлись Bonnier и «Взаимный пенсионный фонд Пойола». В 2005 году акции этого фонда были проданы шведской компании Proventus партнеру компании Bonnier. В результате данной сделки Bonnier и Proventus значительно увеличили свою долю владения компаний. После завершения этой сделки Alma Media продала за 460 миллионов евро бизнес-подразделение «Телевизионная трансляция» компании Almanova, которая полностью находилась во владении компаний Bonnier и Proventus. Предполагалось, что полученная от продажи бизнес-подразделения прибыль будет инвестирована в выкуп варрантов компании Alma Media, которые изначально обращались на фондовой бирже Хельсинки. Стратегическим решением компании Almanova являлось стремление вывести Alma Media на открытый рынок с последующим слиянием с компанией Almanova в новую компанию Alma Media. Акции образовавшейся компании также должны были обращаться на фондовой бирже Хельсинки.

Цель кейса заключается в том, чтобы определить оптимальный способ финансирования расходов на выкуп варрантов, акций Almanova и затрат на размещение акций Alma Media на открытом рынке. С точки зрения финансовой архитектуры данная цель формулируется как определение оптимальной структуры капитала компании.

Нестандартность задачи оценивания оптимальной структуры капитала заключается в том, что:

- при решении задачи выбора структуры оптимального финансирования применялись традиционный инструмент анализа и современные инструменты анализа финансовой архитектуры компании;

- оценка проводится на конец 2005 года, а в качестве традиционного подхода определения структуры капитала была выбрана модель анализа EBIT-EPS:

$$
\frac{\left(E B I T-\text { Interest }_{\text {debt }}\right)(1-T)}{n_{\text {debt }}}=\frac{\left(E B I T-\text { Interest }_{\text {equity }}\right)(1-T)}{n_{\text {equity }}},
$$

где

Interest $_{\text {debt }}$ - процентные выплаты при условии привлечения долга;

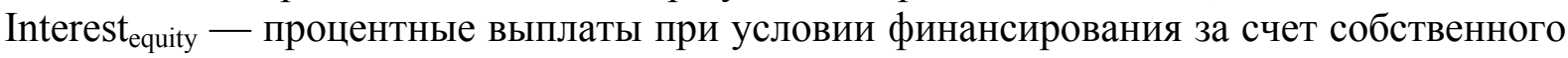
капитала;

$\mathrm{n}_{\text {debt }}$ - количество акций при условии привлечения долга;

$\mathrm{n}_{\text {equity }}$ - количество акций при условии финансирования за счет собственного капитала;

T - ставка налога на прибыль. 
Особенность определения оптимальной структуры капитала для компании Alma Media заключается в том, что помимо возможности финансирования расходов на выкуп акций за счет собственных и заемных средств компания может использовать доход от продажи бизнес-подразделения в размере 324,5 миллиона евро. ${ }^{60}$

В модели вводится предпосылка о темпе роста прибыли. Предположим, что прибыль будет расти темпами, равными темпу роста ВВП в Финляндии за 2005 год, поправленному на 3\%, то есть вырастет на 5\%. В случае финансирования за счет дополнительной эмиссии акций количество выпущенных акций рассчитывается исходя из цены на конец ноября 2005 года. Случай, в котором компания привлекает долг, рассматривается как текущая ситуация Alma Media на момент анализа. Проценты по долгу рассчитываются как те, что показаны в отчетности компании с учетом дополнительных выплат по привлеченному долгу, равному расходам, требующим финансирования. Для расчета точки безразличия между источниками финансирования используется эффективная ставка налога на прибыль в Финляндии 28\%.

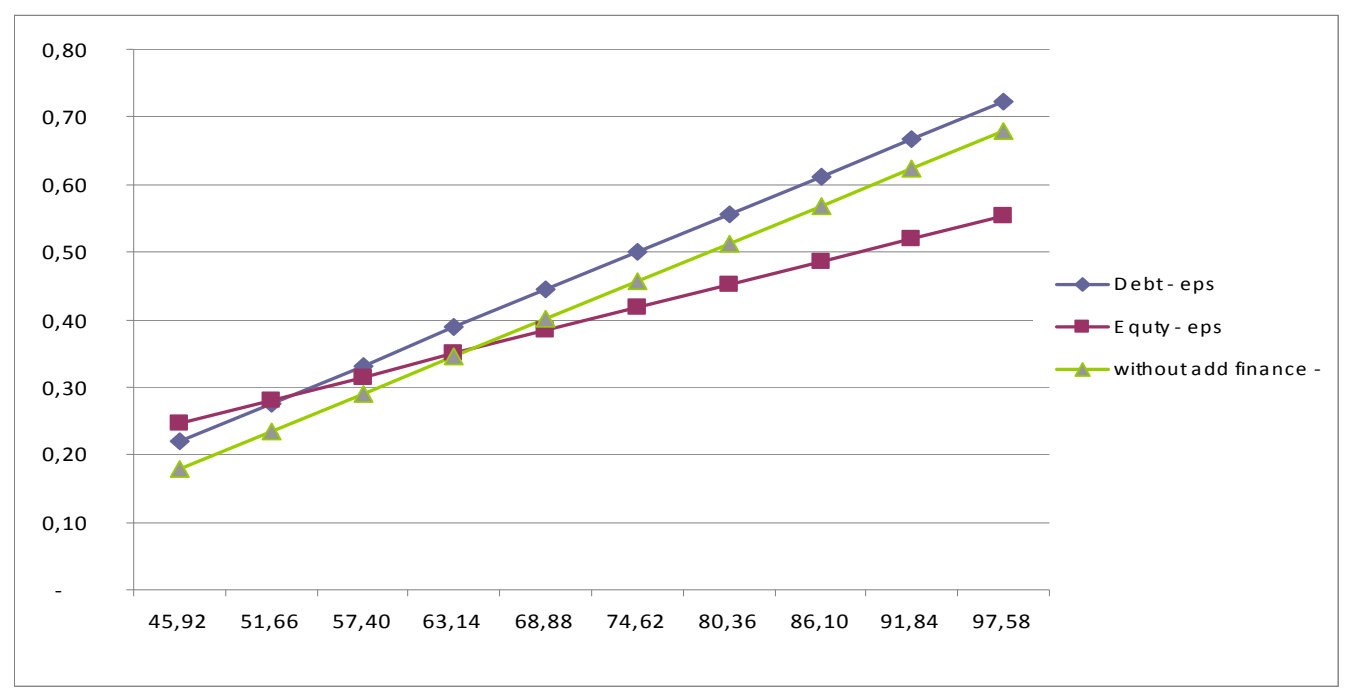

\section{Рисунок 1. Результаты модели EBIT-EPS для компании Alma Media}

Подход EBIT-EPS установил, что при уровне EBIT выше 50 млн евро предпочтительным будет использование долгового финансирования. При меньших значениях EBIT - использование собственного капитала. При этом продажа телевизионного подразделения, согласно модели EBIT-EPS, не должна использоваться для получения недостающего финансирования.

Для определения максимально допустимого уровня долга для компании Alma Media используем метод операционного дохода.

Безрисковая ставка равна ставке по десятилетним облигациям Казначейства США в 2005 году (4,43\%). Предполагаемая процентная ставка берется равной безрисковой, с поправкой на риск компаний с кредитным рейтингом АА $(1,25 \%){ }^{61}$

Отметим, что определение беты компании требует особых расчетов, так как продажа ее телевизионного подразделения изменяет структуру бизнеса. У каждой отрасли и ниши рынка существуют свои риски, которые могут сильно варьироваться, поэтому мы проведем расчет беты компании до и после продажи телевизионного подразделения. Для этого рассчитаем бету для каждого из основных направлений бизнеса компании (газета, предоставление бизнес-информации, интернет-бизнес, телевидение) и взвесим по доле в стоимости компании. Вклад подразделения в стоимость компании рассчитывался как выручка, принесенная подразделением (берется из отчетности), умноженная на

\footnotetext{
${ }^{60}$ Alma Media, годовой отчет 2005.

${ }^{61}$ Damodaran.
}

Выпуск \#4(8), 2008

(C) Электронный журнал Корпоративные Финансы, 2008 
среднеотраслевое отношение оценочной стоимости к выручке (EV/Sales). Выручка по телевизионному подразделению, если бы оно не было продано, принимается равной прошлогодней с поправкой на темп роста отрасли (2,9\%) в 2005 году. ${ }^{62}$ Средние значения по отрасли рассчитывались по европейским компаниям (Alma Media представлена не только в Финляндии, но и в Швеции), которые работают только на соответствующем рынке. В результате были получены следующие значения по отраслевым EV/Sales:

- газеты - 1,75 (по 22 компаниям);63

- $\quad$ предоставление бизнес-информации - 5,29 (по трем компаниям);

- Интернет-бизнес - 8,21 (по пяти компаниям);

- телевидение - 2,64 (по 16 компаниям).

\section{Расчет беты для Alma Media}

Таблица 1.

\begin{tabular}{|l|l|l|l|l|l|}
\hline Подразделение & $\begin{array}{l}\text { Выручка, } \\
\text { млн евро }\end{array}$ & EV/Sales & $\begin{array}{l}\text { EV, млн } \\
\text { евро }\end{array}$ & $\begin{array}{l}\text { Доля } \\
\text { стоимости, \% }\end{array}$ & Бета \\
\hline Газета & 211,6 & 1,75 & 369,27 & 27 & 1,01 \\
\hline Бизнес-информация & 53,8 & 5,29 & 284,64 & 21 & 1,40 \\
\hline Интернет-бизнес & 22,7 & 8,21 & 186,46 & 14 & 1,54 \\
\hline Телевидение & 196,0 & 2,64 & 516,65 & 38 & 1,08 \\
\hline Alma Меdia с телевидением & 484,1 & & 1357,02 & 100 & $\mathbf{1 , 1 9}$ \\
\hline Alma Меdia без телевидения & & & 840,37 & & $\mathbf{1 , 2 6}$ \\
\hline
\end{tabular}

Таким образом, бета Alma Media с телевизионным подразделением равнялась 1,19 , а без него увеличилась до 1,26.

Кроме того, для расчета стандартного отклонения ЕВIT компании мы не можем использовать годы, предшествовавшие моменту рассмотрения кейса, так как в 2001-м ЕВIT было отрицательным (это привело к тому, что стандартное отклонение ЕВIT колеблется около -200\%). Поэтому мы вводим предпосылку о том, что менеджеры компании обладают точным прогнозом (который совпадает с фактическими значениями) по EBIT Alma Media в ближайшие три года. Рассчитанное по результатам 2005-2007 годов стандартное отклонение равно $10,84 \%{ }^{64}$ В результате получаем, что максимально допустимый для компании уровень дополнительного долга составляет 224,4 млн евро.

Рассмотрим также модель APV (Adjusted Present Value) для оценки оптимальной структуры капитала компании.

При использовании этого подхода изначально существует предпосылка о том, что издержки банкротства компании составляют $25 \%$ от ее стоимости, что подтверждается рядом эмпирических исследований. Остальные предпосылки 1 те же, что и для проведенных ранее расчетов.

В результате мы получаем, что оптимальная долговая нагрузка для Alma Media c точки зрения стоимости компании составляет $20 \%$, то есть ее необходимо было увеличить более чем в два раза.

В целом мы можем отметить, что для финансирования выкупа акций менеджмент компании пошел на продажу одного из своих подразделений, что редко используется на практике и необоснованно с точки зрения теоретических моделей. При этом Alma Media могла использовать заемное финансирование операции выкупа благодаря своему низкому уровню текущего долга и высокому кредитному рейтингу.

\footnotetext{
${ }^{62}$ European Audiovisual Observatory, The financial situation of television companies in the European Union (1999_2005), 2006.

63 Данные Bloomberg.

${ }^{64}$ Alma Media, консолидированная финансовая отчетность 2005-2007.
}

Выпуск \#4(8), 2008 (С) Электронный журнал Корпоративные Финансы, 2008 
Можно предположить, что принятое решение являлось на самом деле не способом оптимизации акционерного капитала иди поощрения собственников компании, а было вызвано желанием двух мажоритарных акционеров получить под свой полный контроль одно из наиболее прибыльных подразделений Alma Media. При этом переход на единую акцию не имел под собой экономического обоснования.

\section{Определение оптимальной структуры капитала для компании «РБК Информационные системы»}

ОАО «РБК Информационные системы» является многопрофильным холдингом, основными направлениями бизнеса которого по состоянию на начало 2004 года являлись:

- рынок медиауслуг (газета РБК-daily, порталы РБК, Cnews, Autonews, Quote.ru);

- рынок информационных технологий;

- телевизионный канал РБК-ТВ.

Выручка компании показывала существенный рост (в среднем 50\% в течение предыдущих 3 лет), ${ }^{65}$ и, согласно прогнозам аналитиков, высокие темпы роста (до 50\%) должны были сохраняться в среднесрочной перспективе. Вследствие этого РБК для развития и расширения (в том числе международной экспансии) бизнеса требовались значительные средства, превышающие внутренние ресурсы компании. Соответственно, у холдинга возникла проблема выбора источников финансирования своего развития между заемными и собственными источниками. Таким образом, в начале 2004 года компания РБК столкнулась с классическим кейсом на выбор оптимальной структуры капитала. Рассмотрим решение, принятое компанией, и структуру капитала, которая могла бы быть выбрана, исходя из положений современной теории корпоративных финансов.

12 января 2004 года компания выпустила 14,85 млн новых обыкновенных акций, увеличив тем самым общее количество акций до 114,85 млн. ${ }^{66}$ При этом в 2004 году процентный долг компании вырос с 163,8 млн рублей до 363,3 млн рублей, то есть в 2,2 раза. $^{67}$ Увеличение долгового финансирования велось с помощью открытой ООО «Москоммерцбанк» в феврале 2004 года кредитной линии сроком на 5 лет и с лимитом $\$ 4,5$ млн (ставка кредита $-13,25 \%$ годовых). ${ }^{68}$

Предположим, что в момент принятия решения о выпуске дополнительной эмиссии акций у компании также была возможность выпустить долг на ту же сумму. Метод ЕВITEPS показывает, что для РБК при любом уровне EBIT оптимальным было бы увеличение акционерного капитала, а не выпуск нового долга.

При анализе с помощью модели EBIT-EPS мы предполагали, что ставка процента по кредиту равна той, по которой он был получен месяц спустя после выпуска акций $(13,25 \%)$, так как за это время не произошло событий, которые могли бы оказать значимое влияние на уровень процентных платежей. Отметим, что в данном случае неприменима синтетическая ставка по кредиту, так как она находится на слишком низком уровне для российского рынка (в 1,5 раза ниже ставки рефинансирования ЦБ на 1 января 2004 года). Процентные платежи по долгу без привлечения дополнительных кредитов взяты из отчетности компании по состоянию на 1 января 2005 года. Эффективная ставка налога на прибыль равна 24\%. При этом объем необходимых компании средств рассчитывается как произведение числа акций, которые были эмитированы в действительности 14 января 2008 года на их цену. Предполагается, что дополнительная эмиссия акций компании проводится по цене по состоянию на 1 января 2004 года.

\footnotetext{
${ }^{65}$ РБК, Годовой отчет 2003.

${ }^{66}$ РБК, Годовой отчет 2004.

${ }^{67}$ РБК, Консолидированная финансовая отчетность 2003, 2004.

${ }^{68}$ РБК, Годовой отчет 2004.
}

Выпуск \#4(8), 2008 


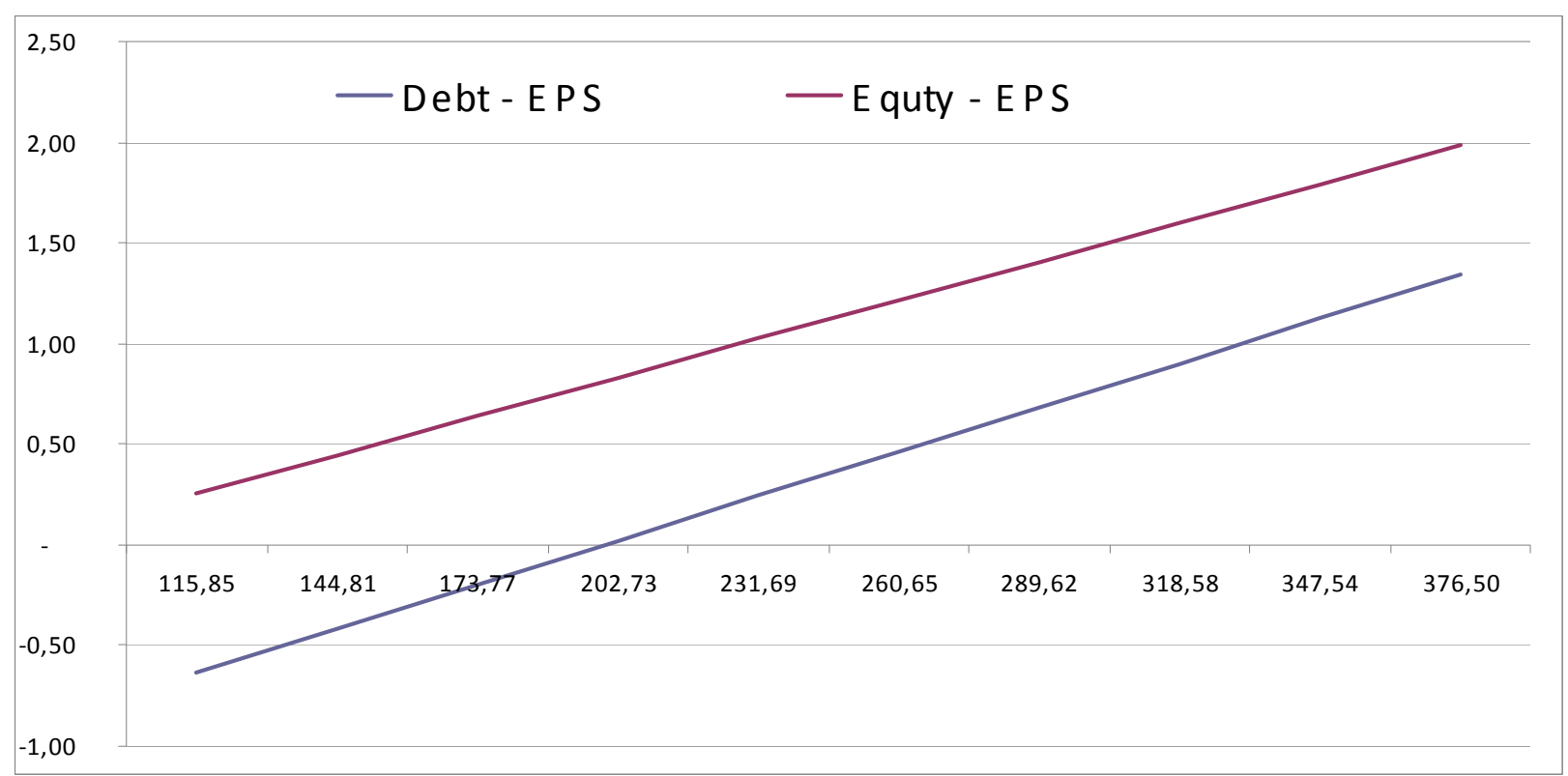

Рисунок 2. Результаты модели ЕВIT-EPS для компании РБК

Использование метода операционного дохода (operating income) на данных компании «РосБизнесКонсалтинг» не представляется возможным, поскольку ввиду высокой изменчивости ЕВIT стандартное отклонение составило 162,25\% (и в будущем оно также оставалось высоким).

Метод APV показал, что более предпочтительным для компании будет оставить текущую структуру капитала, хотя вероятность банкротства составляет лишь 2,5\%. Увеличение долговой нагрузки может привести к существенному росту доли процентных платежей по отношению к ЕВIT. Это, в свою очередь, увеличивает вероятность дефолта.

Следует отметить, что результаты данного метода нечувствительны к такому оценочному параметру, как издержки банкротства. Даже при его значительном увеличении (с 25 до 40\%) оптимальный уровень долга существенно не меняется.

При проведении расчетов по модели APV бета акций компании бралась равной 1,5. ${ }^{69}$ Остальные расчеты делались аналогично проведенным по компании Alma Media, так как мы предполагаем, что РБК является глобальной компанией. Это подтверждается, в частности, тем, что РБК в рассматриваемый период выходила на рынки стран СНГ и Восточной Европы. Данные по деятельности компании взяты из ее финансовой отчетности.

Менеджмент компании РБК использовал для получения средств на развитие компании как собственный, так и заемный капитал. При этом долговая нагрузка (процентный долг к сумме процентного долга и рыночной стоимости собственного капитала компании) увеличилась с 2,6 до 4,1\%. Все рассмотренные методы показали предпочтительность использования собственного капитала, что обусловлено высокой стоимостью кредитных ресурсов в России в рассматриваемый период и невысоким уровнем рентабельности компании из-за ее быстрого развития. Таким образом, менеджмент в некоторой степени следовал логике рассмотренных методов, так как провел дополнительную эмиссию акций. Однако долговая нагрузка компании в 2004 году выросла, хотя и незначительно (но в абсолютных объемах процентный долг вырос в 2,2 раза).

Это может говорить о том, что стандартные методы расчета оптимальной структуры капитала плохо учитывают специфику компании и поэтому менеджеры РБК их не использовали (или вводили другие предпосылки). С другой стороны, причиной решения использовать заемный капитал может быть нежелание собственников - основателей компании «размывать» свою долю. Косвенным свидетельством этого может служить

${ }^{69}$ Сайт Асвата Дамодарана.

Выпуск \#4(8), 2008 
проведенный впоследствии выпуск ADR, держатели которых в намного меньшей степени, чем обычные миноритарные акционеры, оказывают влияние на деятельность компании. Если это предположение является верным, то мы можем сформулировать гипотезу о том, что в России выбор структуры капитала зависит в большей степени не от ее оптимальности с точки зрения стоимости компании, а от интересов ее мажоритарных акционеров или менеджмента.

\section{Сравнительный анализ оптимальной и фактической структуры капитала компаний Alma Media и «РБК Информационные системы»}

На момент рассмотрения кейсов по каждой компании они обладали крайне низкой долей заемных средств (отношение процентных обязательств к сумме процентных обязательства и собственного капитала для Alma Media и РБК составляют соответственно 9 и 2,6\%). В целом столь низкая доля заемных средств не является характерной для развитых стран, но может встречаться в развивающихся странах с ограничениями на рынках капитала.

Отметим, что при решении проблемы выбора структуры капитала Alma Media и РБК должны были преследовать различные цели. Компании «РБК Информационные системы» требовались дополнительные средства для поддержания быстрого роста, в то время как Alma Media планировала провести выкуп варрантов и акций.

При этом методы выявления оптимальной структуры капитала показали, что для РБК предпочтительным является привлечение дополнительного собственного капитала. В то же время Alma Media должна была увеличить долю заемного капитала.

Сходством в политике обеих компаний по определению структуры капитала является то, что и Alma Media, и РБК приняли решения, противоположные теоретически обоснованным:

- компания Alma Media продала свое телевизионное подразделение;

- компания РБК увеличила долю заемных средств с 2,6 до 4,1\%.

Согласно нашей гипотезе, подобное противоречие может объясняться тем, что мажоритарные собственники или менеджмент при принятии решений по структуре капитала руководствуются иными целями, нежели достижение оптимального значения, способствующего максимизации стоимости компании.

В случаe Alma Media eе мажоритарные собственники Bonnier и Proventus решили вывести из компании достаточно прибыльный телевизионный бизнес, получив его в свое полное владение. Холдинг РБК принял решение об увеличении доли заемного капитала, несмотря на его дороговизну, для сохранения доли мажоритарных акционеров - основателей компании.

\section{Выводы}

В ходе работы мы описали кейсы по определению структуры капитала для компаний Alma Media (в 2005 году) и «РБК Информационные системы» (в 2004 году). При этом с помощью использования методов EBIT-EPS, операционных доходов и APV было определено, что для Alma Media оптимальным будет увеличение доли заемных средств в компании до 20\%. В то же время РБК для финансирования развития бизнеса должна была использовать собственные средства, оставив долю заемного капитала на прежнем уровне около $2 \%$.

Но менеджментом обеих компаний были приняты решения, противоречащие приведенным в статье расчетам. В результате этого Alma Media осталась с существенно заниженной долей заемного капитала, что снизило ее эффективность. При этом компания РБК, напротив, увеличила долю заемных средств до слишком высокого уровня, что привело к значительному росту риска банкротства. Alma Media также продала свой телевизионный бизнес, что не было оправданно с точки зрения инвестиционной привлекательности 
компании. В обоих случаях были выдвинуты гипотезы о том, что решения по структуре капитала были приняты под давлением контролирующих акционеров, имеющих собственные интересы, не совпадающие с интересами компании в целом и миноритарных акционеров в частности.

Таким образом, несмотря на существенные различия в развитии экономики и бизнессреды России и Финляндии, в обеих странах компании принимают решения, основываясь в большей степени на интересах контролирующих собственников, а не на стремлении достичь оптимальной структуры капитала. Разумеется, это вызывает негативные эффекты для эффективности компаний и их стоимости.

\section{Список литературы}

1. РБК, Годовые отчеты 2003, 2004.

2. РБК, Консолидированная финансовая отчетность 2003, 2004.

3. Alma Media, годовой отчет 2005.

4. Alma Media, Консолидированная финансовая отчетность 2004-2007.

5. Bloomberg.

6. European Audiovisual Observatory/ The financial situation of television companies in the European Union (1999-2005), 2006. 